\title{
Extreme microallopatric divergence in a cichlid species from Lake Malawi
}

\author{
C. RICO* $\ddagger$ and G. F. TURNER † \\ *School of Biological Sciences, Centre for Ecology, Evolution and Conservation, University of East Anglia, Norwich, NR4 7TJ, UK, \\ †Department of Biological Sciences, University of Hull, Hull, HU6 7RX, UK
}

\begin{abstract}
We demonstrate significant population structuring on an extremely small spatial scale between adjacent demes of a Lake Malawi haplochromine cichlid species of the mbuna group, Pseudotropheus callainos, separated by only $35 \mathrm{~m}$ of habitat discontinuity. This substantiates further the notion that intralacustrine allopatric divergence may help to explain the high level of species richness of the mbuna in comparison to other Malawian cichlids, as well as of the Malawian haplochromines as a whole.
\end{abstract}

Keywords: cichlids, Lake Malawi, microstallites, population structure

\section{Introduction}

The fastest large-scale adaptive radiations in recorded evolutionary history have occurred in Lakes Victoria and Malawi in East Africa. At the last count, Lake Malawi was estimated to contain 659 haplochromine cichlid species, all but two endemic to the lake (Turner et al. 2001) and 50 other fish species, about half of which are endemic (Ribbink 1994). Lake Victoria has very similar levels of species richness and endemicity (Seehausen 2002). These lakes almost certainly harbour the largest number of vertebrate species endemic to any comparably sized area on the planet. Almost all the endemic species are haplochromine cichlid fishes, and the species-rich Malawian and Victorian lineages are related very closely to each other (Meyer 1993; Albertson et al. 1999). In each lake, a great proportion of this diversity is represented by small $(<25 \mathrm{~cm})$, brightly coloured rock dwellers known as 'mbipi' (L. Victoria: Seehausen 1996) and 'mbuna' (L. Malawi: Konings 2001). Why have these ecologically similar lineages undergone such remarkable evolution in both lakes?

Fryer (1959) suggested that allopatric speciation in mbuna could take place within the present-day boundary of Lake Malawi because these fishes are rarely found away

Correspondence: C. Rico. E-Mail: c.rico@uea.ac.uk

$\ddagger$ Present address: Estacion Biologica de Donana, Consejo Superior de investigaciones Cientificas, Avda. M@Luisa s/n, Pab. del Perú, 41013 Sevilla, Spain. from rocky shore habitats, which are distributed patchily within the lake. Allozyme studies have shown genetic differentiation among populations isolated by deep-water trenches or by shorelines of hundreds of kilometres (McKaye et al. 1984). Microsatellite studies have demonstrated population structuring over distances of a few hundred metres of habitat discontinuities (Van Oppen et al. 1997a; Arnegard et al. 1999; Markert et al. 1999). Here, we test whether the population might even be on a much smaller scale than demonstrated hitherto, investigating two samples of an mbuna separated by a waterfall which flows on the southern edge of a sandy beach only $35 \mathrm{~m}$ wide located in the Bay of Ruarwe in Lake Malawi.

\section{Materials and methods}

The study species was the 'pearly' race of Pseudotropheus (Maylandia) callainos. At Ruarwe, both sexes of this species are pure white, apart from several yellow 'eggspots' on the anal fin (Konings 2001). This allows it to be distinguished easily from all other sympatric cichlids. At Nkhata Bay and other sites south of Ruarwe, populations are colour polymorphic, with most individuals pale blue, but with some white and blotched individuals. Although it had been suggested that these might represent a distinct allopatric species, formerly called Pseudotropheus 'zebra cobalt' (Ribbink et al. 1983), it is now believed generally that the two are probably conspecific (Konings 2001). As with many other Malawian cichlids, the generic placement 


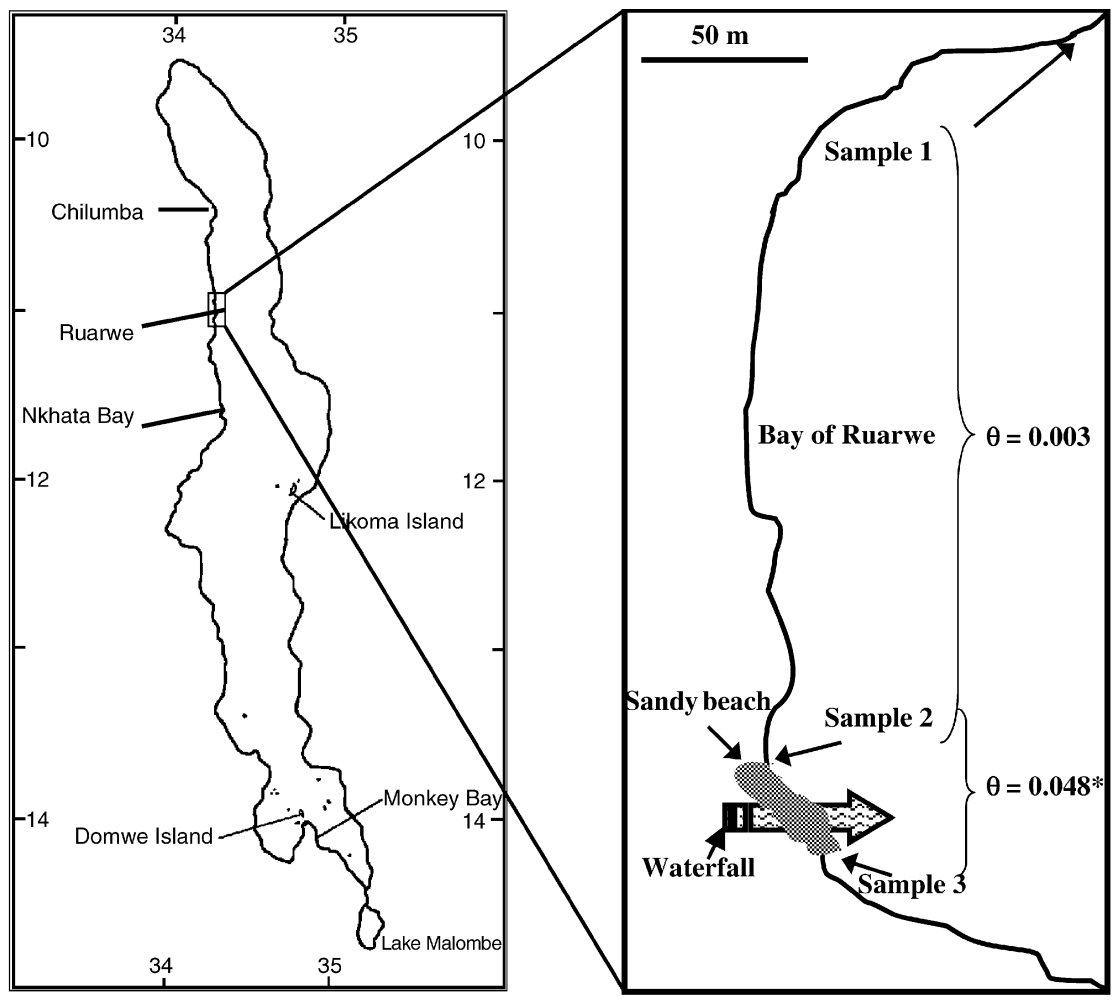

Fig. 1 Partial view of the Bay of Ruarwe on the northwestern shore of Lake Malawi where the sampling area is located (not to scale). Samples of 50 individuals were collected from three sites (1-3 from north to south). The shore between the three sites is a mosaic of rocky and small sandy patches, the longest uninterrupted sandy beach being about $35 \mathrm{~m}$ long represented by the shaded area. There is an inflowing cold-water stream represented by the thick arrow, which flows from the highlands throughout the year on the southern edge of the beach.

of the species is uncertain. Although many recent publications follow Stauffer et al. (1997) in assigning the species to the genus Metriaclima, this is now considered (Condé \& Géry 1999) to be a junior synonym of Maylandia, which itself may still be best considered as a subgenus of Pseudotropheus.

The sampling area is located on the northwestern shore of Lake Malawi at the northern end of the bay of Ruarwe. Samples of 50 individuals were collected from each of three sites. The shore between the three sites is a mosaic of rocky and small sandy patches, the longest uninterrupted sandy beach being about $35 \mathrm{~m}$ long. There is an inflowing cold-water stream (approx. $18^{\circ} \mathrm{C}$, about $5{ }^{\circ} \mathrm{C}$ less than the water of the lake in September), which flows from the highlands throughout the year on the southern edge of the beach. The beach is surrounded by rock cliffs and was inundated up to 1980 when the lake level dropped to an extent that has left it exposed for the last 20 years (Fig. 1). The slope from the shoreline is about $45^{\circ}$ and there are no bottom rocks in depths above $50 \mathrm{~m}$. Two population samples were collected at either side of this beach (sites 2 and 3) while a third sample (sample 1) was collected at about $700 \mathrm{~m}$ from the north edge of the beach (site 1). Sample collection and preservation was as described by Van Oppen et al. (1997a, 1998). The shoreline between sample sites 1 and 2 is uninterrupted rocky habitat (Fig. 1).

Samples were prepared and screened for variation at six polymorphic microsatellite loci as described by Van
Oppen et al. (1997b). The six loci (Kellogg et al. 1995; Van Oppen et al. 1997b) include four perfect dinucleotide repeats (Pzeb1-3 and UNH002), and two imperfect dinucleotide repeats, Pzeb4 and Pzeb5. Allele frequencies, expected $\left(H_{\mathrm{E}}\right)$ and observed $\left(H_{\mathrm{O}}\right)$ heterozygosities, were calculated using genepop 3.1b (Raymond \& Rousset 1995). Samples were tested for linkage disequilibrium and departure from Hardy-Weinberg equilibrium by the Markov chain method. Heterogeneity in allele frequency distribution for all loci, and all pairwise comparisons, was tested based on an assumption of no differentiation.

arlequin 1.1 (Schneider et al. 1997) was used to calculate pairwise fixation indices, based on allele frequency variation using an amova framework to estimate weighted $F$-statistics $(\theta)$ over all loci (Excoffier et al. 1992). The significance of genetic subdivision was assessed using 1000 permutations. Bonferroni corrections were applied to all pairwise tests using a global significance level of 0.05 ( $k=18)$ (Rice 1989).

\section{Results and discussion}

All three samples were highly genetically diverse, showing high heterozygosities at most loci. A total of 36, 32, 20, 13, seven and four alleles were observed at Pzeb1, UNH-002, Pzeb2, Pzeb3, Pzeb4 and Pzeb5, respectively (Table 1). Significant deviations from Hardy-Weinberg equilibrium 


\begin{tabular}{|c|c|c|c|c|c|c|c|c|c|}
\hline & \multicolumn{3}{|l|}{ Pzeb1 } & \multicolumn{3}{|c|}{ Pzeb2 } & \multicolumn{3}{|c|}{ Pzeb3 } \\
\hline & $N A$ & $H_{\mathrm{O}}$ & $H_{\mathrm{E}}$ & $N A$ & $H_{\mathrm{O}}$ & $H_{\mathrm{E}}$ & $N A$ & $H_{\mathrm{O}}$ & $H_{\mathrm{E}}$ \\
\hline \multicolumn{10}{|l|}{ Locus } \\
\hline Site 1 & 35 & $0.82 *$ & 0.97 & 19 & $0.67 *$ & 0.89 & 11 & 0.58 & 0.65 \\
\hline Site 2 & 35 & $0.81 *$ & 0.95 & 19 & $0.66^{*}$ & 0.89 & 11 & 0.56 & 0.62 \\
\hline \multirow[t]{2}{*}{ Site 3} & 21 & $0.75^{*}$ & 0.91 & 13 & $0.64^{*}$ & 0.84 & 8 & 0.52 & 0.60 \\
\hline & \multicolumn{3}{|l|}{ Pzeb4 } & \multicolumn{3}{|c|}{ Pzeb5 } & \multicolumn{3}{|c|}{ UNH-002 } \\
\hline \multicolumn{10}{|l|}{ Locus } \\
\hline Site 1 & 7 & 0.55 & 0.63 & 2 & 0.24 & 0.28 & 25 & $0.73 *$ & 0.92 \\
\hline Site 2 & 7 & 0.56 & 0.64 & 2 & 0.15 & 0.16 & 23 & $0.66 *$ & 0.91 \\
\hline Site 3 & 4 & 0.47 & 0.52 & 4 & 0.20 & 0.24 & 18 & $0.61^{*}$ & 0.91 \\
\hline
\end{tabular}

Table 1 Number of alleles (NA), observed $\left(H_{\mathrm{O}}\right)$ and expected $\left(H_{\mathrm{E}}\right)$ heterozygosity. Significant deviations from Hardy-Weinberg equilibrium are under $H_{0}=\mathrm{HWE}$ and $H_{1}=$ heterozygote deficit

*Sequential Bonferroni-adjusted $P$ significantly different from zero.

in the form of heterozygote deficits were present in three loci (Pzeb1, Pzeb2 and UNH-002). Heterozygote deficiencies were assumed to be due mainly to nonamplifying alleles because true breeding null alleles were found in four of the six loci used in this study in a pedigree test using the closely related species $M$. zebra (Van Oppen et al. 1997a, 1998). No significant heterozygote deficits were found at the loci that had no null alleles in the pedigree test. Null alleles would be of significance only if our estimates for population structure were merely artefacts caused by null alleles. An analysis carried out with only the loci that have no heterozygote deficits (Pzeb 3, 4 and 5) yielded the same level of significance on the $F_{\mathrm{ST}}$ estimates as the analysis carried with all loci $(\theta=0.103, P<0.001)$. Therefore, the presence of null alleles reported by Van Oppen et al. (1997a, 1998) in three of the loci clearly had a negligible effect on the estimates of population differentiation. Exact tests for genotypic linkage disequilibrium confirmed the absence of physical linkage at these loci, as reported previously (Van Oppen et al. 1997a).

Significant $(P<0.001)$ heterogeneity in allele frequency distribution was found for all loci, but one (Pzeb5), between samples collected at opposite sides of the beach and waterfall (samples 2 and 3) and between the sample collected south of the waterfall and that collected $700 \mathrm{~m}$ north from the end of the beach (samples 1 and 3) (Figs 1 and 2). $F_{\mathrm{ST}}$ estimates were also significantly different from zero between these samples $(\theta=0.048, P<0.001$ and $\theta=0.052$, $P<0.001$, respectively). Neither estimate of differentiation was significant for the comparison of the samples from sites 1 and 2 (Fig. 1), which were separated by $700 \mathrm{~m}$ of uninterrupted rocky shoreline $(\theta=0.003, P=0.978)$.

Our $F_{\mathrm{ST}}$ estimates for the populations north and south of the waterfall were approximately three times higher than those estimated by Van Oppen et al. (1997a) for the same species at Nkhata Bay, where populations were separated by sand and deep-water barriers approximately 20-40 times wider. This suggests that the cold-water inflow may be a more significant barrier than the 35-m sandy beach.

The absence of mbuna (excluding a few species specialized to live over soft-bottom habitats) elsewhere than on the rocky shores of Lake Malawi and the presence of colour variants with restricted ranges within the lake led Fryer (1959) to suggest that these fishes were split into genetically isolated populations by habitat barriers such as sandy beaches or deep-water trenches. Experiments by Hill \& Ribbink (1978) demonstrated that mbuna had poor ability to cope with rapid changes in water pressure, as would result from changing water depth. This would render them physiologically incapable of rapidly traversing deep-water barriers if they have to remain near the bottom. Our study suggests that temperature discrepancies of as low as $5{ }^{\circ} \mathrm{C}$ may also act as barriers.

Ribbink et al. (1983) suggested that restricted distributions of mbuna phenotypes were not only the result of stenotopy, but also behavioural philopatry. Several studies have reported that tagged adult mbuna of both sexes and several species tend to remain in relatively small areas for many months or even years (Hert 1992; Robinson 1995). Territorial males of several species returned to their home range from distances up to $2.5 \mathrm{~km}$ when translocated experimentally along continuous rocky shores, demonstrating a surprising homing ability (Hert 1992). Even when released $500 \mathrm{~m}$ offshore in open water, five of 10 males returned within a week, compared to 10 of 12 returning the same distance along rocky shores. Thus, it appears that adult fish are sedentary, but capable of rapid longdistance movement, even across major habitat barriers when required. However, when released $1 \mathrm{~km}$ away on a sandy beach on the other side of a deep-water barrier none of 20 fish returned, although 11 of 17 fish returned the same distance along rocky shores (Hert 1992). This may suggest that lack of dispersal across some habitat barriers is due 


\section{Pzeb 2}

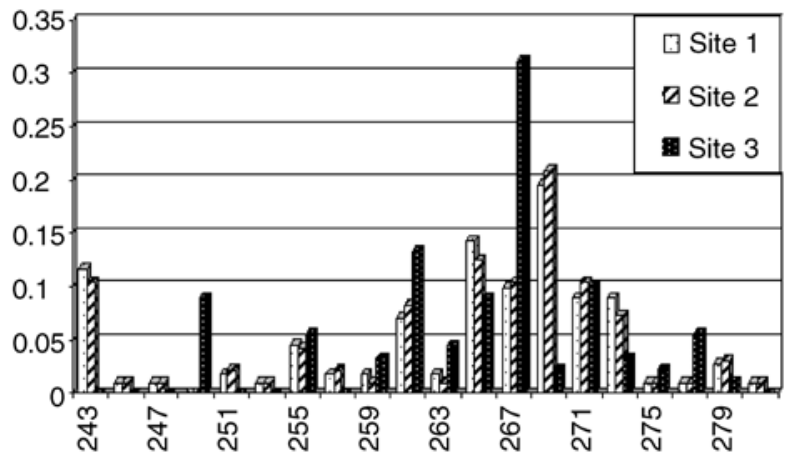

Pzeb 3

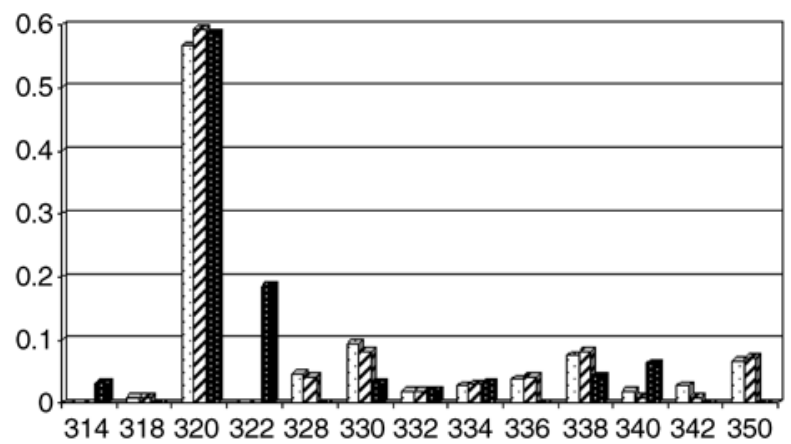

Pzeb 4

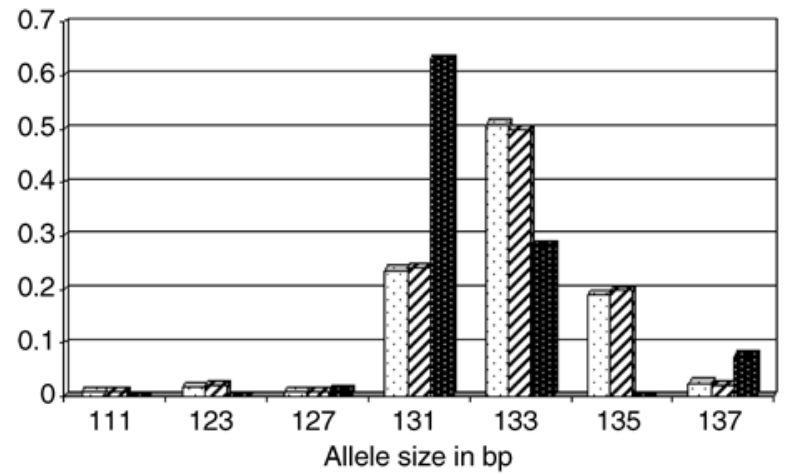

Fig. 2 Allele frequency distributions at loci Pzeb 2, 3 and 4 of $M$. callainos 'pearly' from the three samples collected in the Bay of Ruarwe in Lake Malawi. Significant $(P<0.001)$ heterogeneity in allele frequency distribution was found for all loci, bar one (Pzeb5), between samples collected at either side of the beach and waterfall (samples 2 and 3 ) and between the sample from south of the waterfall and that collected $700 \mathrm{~m}$ north of the beach (samples 1 and 3). To illustrate the extent of differentiation among samples, only loci which show significant differences and have a small number of alleles are shown $(y$ axis $=$ frequency; $x$ axis $=$ allele size in base pairs $)$.

mainly to behavioural choice rather than physiological inability. Dispersal of juveniles has not been studied directly but unlike many marine teleosts, mbuna produce small numbers of large benthic-living offspring and seem to lack a dispersal phase (Hert 1992). Molecular evidence of high levels of population structure caused by relatively small barriers, such as we have shown, suggests that juveniles may disperse as little as do adults. Knight et al. (1999) suggest that males disperse further than females, perhaps in search of a vacant territory. Although much remains to be learned about the mechanisms and patterns of dispersal in mbuna, such knowledge is clearly important for the study of within-lake allopatric speciation.

Lake Malawi is about $600 \mathrm{~km}$ long and up to $80 \mathrm{~km}$ wide. Our results show the development of significant genetic divergence between populations $35 \mathrm{~m}$ apart separated by an identifiable, but small, habitat discontinuity. As this barrier is so small and apparently trivial, there are probably hundreds of such barriers throughout the lake.

We do not debate the evidence for sympatric speciation or allopatric speciation by land barriers in the evolution of cichlid species. However, it is arguable that neither of these mechanisms predict a greater species richness among rocky shore fishes than other cichlids. Fryer's (1959) intralacustrine allopatry theory can make this prediction. However, three further avenues of research remain to be pursued. First, Fryer suggested that rocky habitats provided equally strong barriers to the movement of sandy shore species as do sandy bays for mbuna. This has yet to be tested. If confirmed, we would expect that the species richness of sandy shore lineages be as great as that of the mbuna. Second, support for the importance of intralacustine habitat barriers in accelerating speciation would be enhanced by comparable studies in Lake Victoria. These are currently lacking. Recent studies have shown that the mbipi are also species-rich (Seehausen 1996), although again this depends largely on the demonstration of assortative mating among sympatric colour forms (Seehausen \& van Alphen 1998), extrapolated to allopatric taxa, which have not yet been tested. Third, it has been suggested that sympatric speciation may be driven by disruptive sexual selection acting on male courtship colour (Turner \& Burrows 1995; Higashi et al. 1999). This has suggested an alternative explanation for the species richness of rocky shore cichlids. Seehausen et al. (1997) pointed out that if the transmitted light spectrum is wide, female cichlids will be readily able to distinguish among hues of male courtship dress, and in Lake Victoria clear-water habitats tend to have more species than turbid habitats. Perhaps a synergy of periods of allopatric divergence followed by strong disruptive sexual selection in sypatry may also account for this diversity.

In summary, Fryer's intralacustrine allopatry theory remains an attractive candidate explanation to explain a considerable proportion of the species richness of the cichlid fauna of the African Great Lakes, and particularly to explain much of the variation in species richness among lineages within a lake. 
Our results demonstrate that population structuring in mbuna can be on a much finer geographical scale than proposed previously. Although our study populations do not represent distinct biological species, the demonstration of genetic differentiation on such a small scale indicates the potential role that geographical isolation within the lake may play in allopatric speciation. However, at present this theory still does not provide a satisfactory answer to the key question: what is it about haplochromine cichlid fishes that leads them to speciate so much more rapidly than the many other species that are also split into many genetically isolated populations for long periods?

\section{Acknowledgements}

This work was funded by NERC UK. We thank the government of Malawi for permission to carry out research, the Department of Fisheries for providing facilities and S. Chiotha, M. Chiumia, M. Genner, O. Kachinjika, S. Mapila, O. Msiska, H. Ngulube and R. Robinson for their assistance, and E. Bermingham and M. Taylor and for valuable comments on this manuscript. C.R. gratefully acknowledges A. Mayer and the University of Konstanz for his Guest Professorship, which allowed him to complete this work.

\section{References}

Albertson RC, Markert JA, Danley PD, Kocher TD (1999) Phylogeny of a rapidly evolving clade: the cichlid fishes of Lake Malawi, East Africa. Proceedings of the National Academy of Sciences of the USA, 96, 5107-5110.

Arnegard ME, Markert JA, Danley PD, Stauffer JR, Ambali AJ, Kocher TD (1999) Population structure and colour variation of the cichlid fish Labeotropheus fuelleborni Ahl along a recently formed archipelago of rocky habitat patches in southern Lake Malawi. Proceedings of the Royal Society of London B, 266, 119-130.

Condé B, Géry J (1999) Maylandia Meyer et Foerster, 1984, un nom générique disponible (Teleostei, Perciformes, Cichlidae). Revue Française d'Aquariologie et de Herpetologie, 26, 21-22.

Excoffier L, Smouse PE, Quattro JM (1992) Analysis of molecular variance inferred from metric distances among DNA haplotypes - application to human mitochondrial DNA restriction data. Genetics, 131, 479-491.

Fryer G (1959) The trophic interrelationships and ecology of some of the littoral communities of Lake Nyasa with special reference to the fishes, and a discussion on the evolution of a group of rock-frequenting Cichlidae. Proceedings of the Zoological Society of London, 132, 153-281.

Hert E (1992) Homing and home-site fidelity in rock-dwelling cichlids (Pisces: Teleostei) of Lake Malawi, Africa. Environmental Biology of Fishes, 33, 229-237.

Higashi M, Takimoto G, Yamamura N (1999) Sympatric speciation by sexual selection. Nature, 402, 523-526.

Hill BJ, Ribbink AJ (1978) Depth equilibration of a shallow water cichlid fish. Journal of Fish Biology, 13, 741-745.

Kellogg KA, Markert JA, Stauffer JR, Kocher TD (1995) Microsatellite variation demonstrates multiple paternity in lekking cichlid fishes from Lake Malawi, Africa. Proceedings of the Royal Society of London B, 260, 79-84.

Knight ME, Turner GF, van Oppen MJH, Rico C, Hewitt GM (1999) Evidence for male-biased dispersal in Lake Malawi cichlids from microsatellites. Molecular Ecology, 8, 1521-1527.

Konings A (2001) Malawi Cichlids in Their Natural Habitat, 3rd edn. Cichlid Press, El Paso, Texas, USA.

Markert JA, Arnegard ME, Danley PD, Kocher TD (1999) Biogeography and population genetics of the Lake Malawi cichlid Melanochromis auratus: habitat transience, philopatry and speciation. Molecular Ecology, 8, 1013-1026.

McKaye KR, Kocher TD, Reinthal PN, Harrison R, Kornfield I (1984) Genetic evidence for allopatric and sympatric differentiation among color morphs of a Lake Malawi cichlid fish. Evolution, 38, 215-219.

Meyer A (1993) Phylogenetic relationships and evolutionary processes in east-African cichlid fishes. Trends in Ecology and Evolution, 8, 279-284.

Raymond M, Rousset F (1995) Genepop (Version-1.2) - population genetics software for exact tests and ecumenicism. Journal of Heredity, 86, 248-249.

Ribbink AJ (1994) Speciation mechanisms in Lake Malawi cichlids: a critical review. Archiv für Hydrobiologie Beiheft Ergebnisse der Limnologie, 44, 139-160.

Ribbink AJ, Marsh BA, Marsh AC, Ribbink AC, Sharp BJ (1983) A preliminary survey of the cichlid fishes of rocky habitats in Lake Malawi. South African Journal of Zoology, 18, 149-310.

Rice WR (1989) Analyzing tables of statistical tests. Evolution, 43, 223-225.

Robinson RL (1995) The dynamics of space use in some Lake Malawi Fishes. PhD Thesis, Rhodes University.

Schneider S, Kueffer J-M, Roessli D, Excoffier L (1997) Arlequin 1.2: a Software for Population Genetic Data Analysis. Genetics and Biometry Laboratory, University of Geneva, Switzerland.

Seehausen O (1996) Lake Victoria Rock Cichlids. Verduijn Cichlids, Germany.

Seehausen O (2002) Patterns in fish radiation are compatible with Pleistocene desiccation of Lake Victoria and 14600 year history for its cichlid species flock. Proceedings of the Royal Society of London B, 269, 491-497.

Seehausen O, van Alphen JJM (1998) The effect of male coloration on female mate choice in closely related Lake Victoria cichlids (Haplochromis nyererei complex). Behavioural Ecology and Sociobiology, 42, 1-8.

Seehausen O, van Alphen JJM, Witte F (1997) Cichlid fish diversity threatened by eutrophication that curbs sexual selection. Science, 277, 1808-1811.

Stauffer JR, Bowers NJ, Kellogg KA, McKaye KR (1997) A revision of the blue-black Pseudotropheus zebra (Teleostei: Cichlidae) complex from Lake Malawi, Africa, with a description of a new genus and ten new species. Proceedings of the Academy of Natural Sciences of Philadelphia, 148, 189-230.

Turner GF, Burrows MT (1995) A model of sympatric speciation by sexual selection. Proceedings of the Royal Society of London B, 260, 287-292.

Turner GF, Seehausen O, Knight ME, Allender CJ, Robinson RL (2001) How many cichlid fishes are there in African Lakes? Molecular Ecology, 10, 793-806.

Van Oppen MJH, Rico C, Deutsch JC, Turner GF, Hewitt GM (1997b) Isolation and characterization of microsatellite loci in the cichlid fish Pseudotropheus zebra. Molecular Ecology, 6, 387-388. 
Van Oppen MJH, Turner GF, Rico C et al. (1997a) Unusually finescale genetic structuring found in rapidly speciating Malawi cichlid fishes. Proceedings of the Royal Society of London B, 264, 1803-1812.

Van Oppen MJH, Turner GF, Rico C et al. (1998) Assortative mating among rock-dwelling cichlid fishes supports high estimates of species richness from Lake Malawi. Molecular Ecology, 7, 991-1001.
Ciro Rico is a lecturer in molecular ecology at the University of East Anglia, with a particular interest in fishes. George Turner is Professor of Evolutionary Biology and Biodiversity at the University of Hull, and is principally interested in the evolution of African cichlid fish. 